authors set forth their method in detail, and they find that it is possible to measure the oxygen pressure in blood drawn directly from a vessel in man to within about $2 \mathrm{~mm}$. on the average, and they confirm experimentally the dissociation curres for venous blood calculated by Douglas, Haldane, and others, as well as the observations of Meakins and Davies on the great range of unsaturation of blood from the basilar vein when the arm is exposed to widely differing temperatures. The experiments indicate a fifty-fold alteration in the volume of blood traversing the skin of the arm per minute.-The Effects of Adrenalin upon Respiration, by Ff. Roberts. It has long been known that adrenalin, when injected into an animal, induces a profound change in respiration. The author, after noting the results of previous observers-from 1895 onwards-describes his own observations on anæsthetised rabbits and cats. The Parke-Davis $0 \cdot 1$ per cent. solution was used-the dose commonly employed was 1 c.cm. of 0.01 per cent. adrenalin, sometimes 1 c.cm. of 0.005 per cent. or of 0.1 per cent. The tube connecting the artery and manometer for the blood pressure experiments was filled with pure Ringer's solution. Adrenalin in large doses, besides causing diminution and temporary arrest of respiration. causes alteration in rate, and may cause Cheyne-Stokes respiration, and the diminution and arrest occur when there is no change in blood pressure and are mainly central in origin. The respiratory effects are caused by sudden anæmia of the respiratory centre due to vaso-constriction. The author found no evidence that adrenalin causes nervous impulses from the periphery.-O Other communications include The Action of Carbon Dioxide on Salt and Water Distribution in Blood, by Genko Mukai; The Measurement of the Oxygen Content of the Mixed Venous Blood, and of the Volume of Blood Circulating per Minute, by J. Barcroft, F. J. W. Roughton, and R. Shoji; Variations in Alveolar Carbon Dioxide Pressure in Relation to Meals, by E. C. Dodds and T. Izod Bennett; Studies on the Physiology of Capillaries, by August Krogh; On the Path of Conduction between Auricle and Ventricle in the Amphibian and Reptilian Heart. by D. T. Barry; The Electrical Response of Denervated Muscle, by E. D. Adrian: The Nature of the Isometric Twitch, by W. Hartree and A. V. Hill; The Relation of Pulse Pressure to the Output of the Heart (as investigated on the heart-lung preparation), by Ruth Skelton; and Exosmosis from Animal Cells, by J. Gray.

In the American Jocrnal of Ophthammology for October G. F. Garraghan writes of a case of papilloma of the cornea in a man of 70. A tumour grew from the sclero-corneal limbus and attained such size as to overlap more than half the cornea. It was excised and, histologically, showed the structure of a papilloma. It subsequently recurred more than once. These tumours are rare; they occasionally become malignant.-F. Yano describes a typical circinate retinitis in a boy of 13. It is only in old people that this disease is usually observed. The vision was down to 0 in one eye and $0 \cdot 1$ in the other. The ring of white exudation enclosed both macula and disc. At the macula itself in each eye was a white plaque of exudation.-A. C. Macleish describes keratitis caused by excessive sugar ingestion. Over-indulgence in sweets by children is said to be responsible for many cases of conjunctivitis, blepharitis, phlyctenules, and facial eruptions. In the case described there was a distinct interstitial keratitis in a child of 3 . There was a negative Wassermann reaction. It was found that the child ate a large quantity of sugar daily; when this was stopped the trouble disappeared, recurring when the interdict against sweets was removed.-Oscar Dodd reports a case of repeated operations for glaucoma. After a recurrence following upon a Lagrange operation, a sclero-corneal trephining operation was performed. This was followed by hypotony, iritis, and cataract. After extraction of the cataract the tension again went up and a second trephining operation was performed. The trephine hole got blocked up with thickened membrane, which was subsequently removed. There was a family history of glaucoma in this case. but the second eye did well after a single operation.Ellice M. Alger describes three cases of word-blindness. One of these cases was associated with an attack of right-sided hemiplegia in a man of 59 with a positive Wassermann reaction, leaving a right homonymous hemianopsia, with a total disability to read letters or words though visual acuity was good, numbers being read normally. 'This disability gradually disappeared, although the hemianopsia remained. The other two cases were congenital. Visual memories seem to be stored in the region of the left angular gyrus in righthanded people, and the theory of acquired nrordblindness is that the connexion between the visual centre in the occipital lobe and the angular gyrus is somehow interrupted. In the case of congenital wordblindness the defect is probably in the development of the cortical centre itself and may be of varying severity. The importance of recognising the condition lies in being able to disabuse the minds of the parents or teachers who often take the inability to read as stupidity, while all the time the mental condition of the child may be normal in all other respects. Improvement may be effected by special methods of teaching. -Eugene M. Blake in a paper entitled Ocular Changes in Infantile Scurvy states that exophthalmos due to hæmorrhage into the orbit is a not infrequent symptom of the infantile scurvy, and was first described by Sir Thomas Barlow. It may even be the first symptom, and the child may first be brought to see the oculist. When the correct diagnosis was established in this case the diet was changed from artificial foods to fresh cow's milk and orange-juice, and the child quickly recovered under antiscorbutic measures.-The notes in this number include illustrations of a foreign. body spud illuminator by $W$. $H$. Lowell and a new test-card by J. M. Thorington.



\section{AN OPERATING HAND-LAMP FOR OPHTHALMIC WORK.}

For several months I have been using a hand-lamp in which the source of illumination is the "pointolite" electric lamp of the Ediswan Co., and as I have been so satisfied with it in all operations on the eye, I venture to bring it to the notice of ophthalmic surgeons. The lamp is of 30 candle-power and is enclosed in a

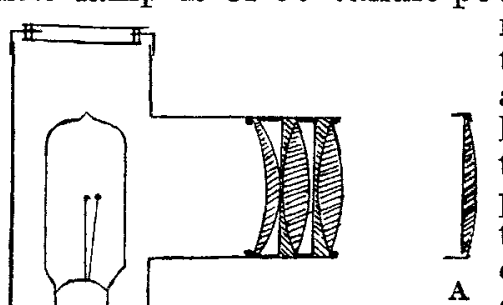
metal case with an aperture on one side in which a system of achromatic lenses is so fixed that the emergent rays are parallel. By this means the field of operation is evenly illuminated by a disc of light free from all shadows. A resistance is supplied with each lamp, whereby it can be used with a direct current from the main of any voltage between 100 and 250 , and a special lamp can be got to work on any direct current down to 32 volts. Up to the present, however, a lamp has not been constructed for an alternating current. A convex auxiliary lens (A) of 3 dioptres can be adjusted in front of the fixed lens in order to bring the light to a focus. An opaque capsule after cataract extraction, no matter how thin it may be, is thereby brought so clearly into view that capsulotomy operations can be performed with great precision. 'The lamp can be used for a considerable length of time without any inconvenience from heating. It is made by John Trotter, Ltd., Gordon-street, Glasgow.
Glasgow.
A. Mattland Ramsay, M.D. Glasg. 


\section{THE LANCET.}

\section{LONDON : SATURDAY, DECEMBER 1\%, 1921.}

\section{Municipal Health Services.}

As may be seen from a brief report in another column, medical practitioners in Willesden have now met the executive committees of local associations of ratepayers in a discussion of the health policy of the Urban District Council as set forth in the medical officer's forty-fifth annual health report. The memorandum, drawn up br a special committee of the B.M.A., Willesden division, criticising the Council's health policy, was before this meeting on Dec. 7th and formed the basis of discussion. No formal resolution was passed, but the tenor of opinion was in harmony with Resolution 7 passed on Nov. 15th-viz., "The division calls the attention of the Willesden rate payers to the health policy of their council, which threatens to destrov the freedom not only of the medical profession but of every individual in the community, and urges the ratepayers strenuously to oppose at the next municipal election those who are responsible for a policy which the medical profession of Willesden considers to be a serious and increasing menace to the public health." 'Then the ratepayers invited the doctors to coopperate in selecting municipal candidates to oppose the existing health policy. Two medical men present at the meeting were willing to become such candidates. It was pointed out by one of the medical speakers that doctors unable to serve on the Council would be ready with their advice if coopted on the Health Committee. A local advisory medical council was suggested by another speaker as the right agency for putting health matters in the urban district upon right lines. Finally, the ratepayers expressed their appreciation of the opportunity afforded to them of conferring on local health problems with members of the medical profession, and ther expressed a wish that such opportunities should be encouraged.

In Willesden it is the municipal hospital around which has centred the hottest part of the controversy. To this hospital the private practitioner has no access, and it would therefore be fair to let the Willesden health service stand or fall by the success of this nearly unique experiment, provided that those who run it have had the materials to hand for making it the success at which they were striving. A speaker at last week's meeting spoke of this hospital as a disgrace. But, as may be seen from the medical superintendent's annual statement, which appears on p. 85 of the health report, he had there to complain, in the same terms as a year ago, of a shortage of beds, of an inadequate nursing staff, and of insufficient medical help. In the vear 1920, with 199 available beds, 2608 patients were dealt with by a staft of 51 nurses and two medical officers; the sickness-rate among the nurses was high, and at no time was there a clean bill of health among them; the resident medical officers were on duty seven days a week, with no break from year end to year end save for annual leave. In this hospital during the year 1920 the following fever cases were admitted : Scarlet 445 , diphtheria 605 , other infections 63 , including typhoid 8 infantile diarrhoea 16, and ervsipelas 8. Pressure

1 THE LANCET, Nov. 26th, p. 1124. upon the maternity beds was continuous; 470 cases were dealt with, as compared with 239 in the previous year; complications included placenta prævia 6 , contracted pelvis 5, eclampsia 2, pelvic inflammation 5, sapræmia and septicæmia 10. Gynæcological cases numbered 81, including incomplete abortion 19 , and acute mastitis 8.524 anæsthetics were administered to operation cases, amongst them tonsillotomy 340 , phimosis 44 , abscess and appendicectomy each 19, for hernias of various forms 16. This amount of work is claimed to be equal to that ordinarily done at a hospital double the size, and in the view of the medical superintendent it implies an enormous strain on the limited resources. It was alleged at last week's meeting that most of the non-infectious cases might have been treated at home. There are 72 beds at the Willesden Hospital, and 330 occupied beds at the infirmary in Acton-lane. London hospitals, it was said at the meeting, were available for Willesden patients. The matter of hospital accommodation in Willesden is certainly one for the ratepayers to look into.

The health policy of the Willesden Council raises a profound question of principle which demands broad and statesmanlike handling. Preventive and curative medicine are at bottom one and indivisible. There may appear to be one glory of the sun and one glory of the moon, and the larger luminary sometimes has its radiance completely obscured by the dark side of the smaller, but the source of light is the same. It is becoming a truism to insist that the general practitioner is now and always will be the chief agent of preventive medicine. The preventist becomes all too readily a mere cataloguer of morbid conditions in relation to certain lines of civic conduct. The public vaccinator is the embodiment of business in the prevention of small-pox, but what service would he be to the community should the influence of the practitioner in the home so wane that parents lost faith in vaccination and refused to submit their children to it. Inspection of children of school age becomes a weariness to the flesh of medical men and women engaged in it, unless combined with some kind of treatment which allows them to see the fruition of their labours. In this respect, no doubt inevitably, the medical staff of the London County Council is sadly handicapped. The remedy, which is only the concentrated wisdom of the Dawson Report, is to abolish as far as possible the cleavage between preventive and curative work. It is impossible to prevent evils which you do not foresee. A practical knowledge of ill-health is the only way to acquire a real insight into the conditions of health, and the search for the earliest manifestations of disease is the chief stand-by of preventive medicine. Like goodness or purity, health is not an attainable ideal, and the immunity which appears to last is that produced by repeated small contacts with morbid influences. Innocence has little chance in an. epidemic. As a nation we are proud of our administrative flexibility, and there is much to be said for each area solving its own public health problems. Willesden and Bradford have both had visions of a municipal health service without the help of the general practitioner; and indeed the branches of practice touched by municipal clinics were almost untouched by clinical medicine. Curative work on an individualistic basis had left out to a remarkable extent any effective supervision of maternity, of the nursling, and of the pre-school child. The gauntlet has now been thrown down. The Willesden division of the B.M.A. has inquired of the parent body how it is that members of the Association can be found to 